\title{
Reading as a source of knowledge
}

\section{René van Woudenberg ${ }^{1}$}

Received: 26 May 2018 / Accepted: 4 December 2018 / Published online: 13 December 2018 (c) The Author(s) 2018

\begin{abstract}
This paper argues that reading is a source of knowledge. Epistemologists have virtually ignored reading as a source of knowledge. This paper argues, first, that reading is not to be equated with attending to testimony, and second that it cannot be reduced to perception. Next an analysis of reading is offered and the source of knowledge that reading is further delineated. Finally it is argued that the source that reading is, can be both transmissive and generative, is non-basic, once was a non-essential but has become essential for many people, and can be unique.
\end{abstract}

Keywords Sources of knowledge $\cdot$ Testimony $\cdot$ Perception $\cdot$ Reading

\section{Introduction}

I shall be arguing that reading is a source of knowing or warranted belief. ${ }^{1}$ Perception, memory, consciousness and reason have standardly been called sources of knowledge (e.g. Chisholm 1977: p. 122; Audi 1998: part I). As of lately testimony has been explicitly added to this illustrious list (Coady 1992: p. 6; Plantinga 1993: p. 77; Audi 1998: ch. 5; Lackey 2008; McMyler 2011: pp. 4-5; Faulkner 2011; Gelfert 2014). ${ }^{2}$

\footnotetext{
1 In this paper, "source of knowledge" should be read as shorthand for "source of knowledge or warranted belief", where "warrant" is a positive epistemic status but doesn't entail truth.

2 Other important discussions of testimony don't call testimony a source of knowledge, e.g. Foley (2001).

3 Listening intuitively also qualifies as a source of knowledge. In what follows I shall focus exclusively on reading, leaving it for another occasion to explore similarities and dissimilarities between reading and listening.

4 None of the following textbooks and non-textbooks even mention reading: Alston (1993), Audi (1998), BonJour (2002), Chisholm (1957), Dancy (1985), Dretske (1969), Gendler and Hawthorne (2006), Moser (1989), Plantinga (1993) and Pritchard (2006). The only philosopher on the analytic side that I know of who has written about reading is Wittgenstein (2009), sections 156-171; the concern there, however, is not epistemological.
}

$凶$ René van Woudenberg

R.van.Woudenberg@vu.nl

1 Department of Philosophy, Vrije Universiteit, De Boelelaan 1105, 1081 HV Amsterdam, The Netherlands 
One wonders, however, why certain items that intuitively seem to qualify as a "source of knowledge", such as reading, ${ }^{3}$ occur on no epistemologist's list of sources. ${ }^{4}$

One wonders, for it has been suggested that a source of knowledge is that "from" which knowledge or warranted belief "comes". (Moser et al. 1998: p. 101; Audi 2002: p. 82) It has also been suggested that a source of knowledge is "roughly, something in the life of a knower ... that yields belief constituting knowledge" (Audi 2002: p. 72). Given these suggestions, reading would seem to qualify as a source, as much knowledge that we have does "come from" reading. In this paper I discuss two possible explanations why epistemologists in the broadly analytic tradition have never considered reading as a source of knowledge, and argue that both are unsatisfactory. The first explanation is that reading is just one form of attending to testimony and hence requires no special attention (Sect. 1), the second that reading is a special case of perception and hence requires no special attention (Sect. 2). In Sect. 3 I offer an analysis of reading, while Sect. 4 gives a richer delineation of the source of knowledge that is associated with reading. Section 5 applies a number of epistemological distinctions that can be found in the literature to this source, so as to further delineate its nature. The final section summarizes the main conclusions.

\section{Reading isn't necessarily attending to testimony}

The first possible explanation that I want to consider as to why reading isn't considered as a separate source of knowledge is that reading is just an instantiation of the more general phenomenon of acquiring knowledge through testimony. The idea is that acquiring knowledge through testimony comes in a variety of forms of which reading is one, listening another, and that whatever epistemically relevant can be said about acquiring knowledge through testimony, carries over to reading. Hence, so the explanation goes, there is no need for epistemologists to pay special attention to reading.

In order to be able to evaluate this explanation, we need to be clear about what testimony is. Various accounts of testimony have been offered. I will discuss three such accounts and argue that on each of them knowledge acquired through reading is not identical with knowledge acquired through testimony. C.A.J. Coady has offered the following account of 'natural' testimony (as opposed to 'formal' testimony of the sort that is offered in court rooms):

A speaker $\mathrm{S}$ testifies by making some statement $\mathrm{p}$, iff

(1) S's stating that $\mathrm{p}$ is evidence that $\mathrm{p}$ and is offered as evidence that $\mathrm{p}$

(2) $\mathrm{S}$ has the relevant competence, authority, or credentials to state truly that $\mathrm{p}$

(3) S's statement that $\mathrm{p}$ is relevant to some disputed or unresolved question (which may or may not be whether p?) and is directed to those who are in need of evidence on the matter. (Coady 1992: p. 42)

There are two points I should like to make about Coady's account. First, given this account of testimony there are many cases of acquiring knowledge or warranted belief through reading that just aren't cases of acquiring knowledge or warranted belief through testimony. Suppose you open a copy of Graham Greene's A Gun for 
Hire, read the opening sentence "Murder didn't mean much to Raven", and thereby acquire the knowledge that Greene's novel opens with that sentence, then you aren't acquiring this knowledge on the basis of Coadyan testimony, for condition (1) isn't satisfied: Greene doesn't offer his statement as evidence that murder didn't mean much to Raven; nor is condition (3) satisfied: Greene's opening sentence isn't relevant to some disputed or unresolved question, and it isn't directed to people who are in need of evidence on the matter of Raven. And this isn't an isolated case. All of the following are things one may come to know, in the contexts sketched between square brackets, through reading, without that knowledge qualifying as being acquired on the basis of Coadyan testimony (for ease of future reference I include the example just given):

(a) That the first line Graham Greene's novel reads "Murder didn't mean much to Raven" [you have opened the book that you know is written by Graham Greene, and have read the opening sentence]

(b) That the text contains a lot of metaphorical expressions [you have read the text and noticed this fact]

(c) That the poem is a sonnet [you are familiar with the formal characteristics of a sonnet]

(d) That the book is humorous [the writer doesn't say or imply so much, but upon reading you find yourself laughing]

(e) That the article contains an invalid argument [you followed the argument on offer, and notice that the conclusions doesn't follow from the argument]

(f) That the review is based on a misunderstanding of the book [you know the book very well]

(g) That the book is a warning call not to harbor grudges in one's heart [this point is not explicitly stated, but from the development of the book's main character you conclude so much]

(h) That the author of the novel assumes that $\mathrm{p}$ [not that he says this explicitly, but it is the inevitable though unobvious conclusion you must draw, given the points that the author does explicitly make]

(i) That the author is intimately familiar with the Scottish Enlightenment [you are an historian that specializes in that period, and even though the book is not a history book, it contains so many adequate allusions to the Scottish Enlightenment, that the conclusion forces itself upon you]

(j) That what the Dutch did in the Caribbean was wrong [the reader is offered a 'clean' neutral statement of facts and figures without the author making any moral or evaluative statement whatsoever]

(k) That the square root of 2 is not a rational number [you have followed and comprehended the proof that was offered, and judged it, rightly, to be sound]

The point of this list is not that these things cannot be known through Coadyan testimony. For surely there are contexts, others than the ones indicated between the square brackets, in which one can and does come to know the things described on the list on the basis of Coadyan testimony. Knowledge of all the propositions listed can be acquired when Coady's three conditions are satisfied. Rather, the point of the list is that one can come to know these things through reading in a way that does not qualify as believing on the basis of Coadyan testimony, viz. in the contexts that are sketched 
between the square brackets. For in none of these cases are Coady's three conditions jointly satisfied. Condition (1) is not satisfied in any of the cases on the list, as the propositions specified aren't offered as evidence. Neither is condition (2) satisfied: the sketches of the contexts provide no indication about the authors' competence, credentials, and authority. Nor is condition (3) satisfied, as the propositions aren't relevant to some disputed or unresolved question, nor are they directed to people who are in need of evidence on the matters at hand. But even though Coady's conditions aren't jointly satisfied, and so knowing the specified propositions in the contexts as sketched cannot be considered as knowledge based on Coadyan testimony, knowing the specified propositions (in the contexts specified) does qualify as knowledge acquired through reading. From which it follows that reading isn't coextensive with attending to Coadyan testimony.

My second point about Coady's account is that, as Jennifer Lackey has argued, it doesn't capture what we ordinarily take testimony to be, as there are clear cases of testimony that don't satisfy (1), (2) and/or (3). Statements in posthumously published private journals and diaries that were never intended by their writers to be read by others, fail Coadyan condition (1): they aren't offered as evidence, nor need they be relevant to some disputed question. But now suppose, to adapt an example from Lackey (2008: p. 18), you read Sylvia Plath's posthumously published diary in which she says that she was regularly deeply depressed. Then you likely come to know that she was regularly deeply depressed. When asked what the epistemic source of your knowledge is, the intuitively correct answer is that it is testimony. For you don't know this through sense perception (you haven't seen her depressed), nor through memory (you don't remember it), or reason (you don't derive this as a conclusion from a number of facts that you are aware of) or introspection or any combination of these sources. You acquired this knowledge from an expression of Plath's own thoughts-her thoughts are, for you, testimony. This example also shows that Coady's condition (3) isn't necessary for someone's testifying: after reading her diary, you will know through Plath's own testimony that she was regularly depressed, but you had no evidential needs.

As Lackey (2008: p. 17) has also argued, Coady's condition (2) isn't necessary for what we ordinarily take testimony to be either. This condition entails that one doesn't testify, unless one has the competence, authority or credentials to state truly that $\mathrm{p}$. Now someone who lacks these properties may not be a very reliable testifier. But she is still capable of testifying. Her testimony may not be an epistemically good source of belief. But she can testify nonetheless. People who give false testimonies about, for example, others testify nonetheless; they testify falsely. And false testimony is testimony as much as a bad squash player is still a squash player.

All of this is obviously relevant for my argument that reading is a source of knowledge that is not coextensive with attending to testimony. For if Coady's account of testimony is wrongheaded, my list of things that we may come to know through reading even though that doesn't qualify as attending to Coadyan testimony won't bear much weight. Let us therefore turn to another account and see whether on that account acquiring knowledge of the things that are on the list (in the contexts as sketched between square brackets), does qualify as the acquisition of knowledge through testimony. On this account, testimony is "people's telling us things" (Audi 1998: p. 131), 
or "tellings generally" with "no restrictions either on subject matter or on the speakers epistemic relation to it" (Fricker 1995: pp. 396-7). Related is the view that testimony requires "only that it be a statement of someone's thoughts or beliefs, which they might direct to the world at large and to no one in particular" (Sosa 1991: p. 219). The essence of this broad view, as Lackey (2008: p. 20) states, can be put as follows:

$\mathrm{S}$ testifies that $\mathrm{p}$, iff S's statement that $\mathrm{p}$ is an expression of S's thought that $\mathrm{p}$.

It is clear that this account is not vulnerable to the objections just raised against Coady's account. On this account Sylvia Plath's statements in her private diary qualify as testimony, as do expressions of thoughts that are false. That is to say: on this account one can testify that $\mathrm{p}$, even if one doesn't offer one's thought as evidence, even if one doesn't have the relevant competence, authority or credentials to state truly that $\mathrm{p}$ (i.e. even if the testimony is false), and even if one doesn't express one's thought that $\mathrm{p}$ to people who are in need of evidence regarding $\mathrm{p}$.

Regarding the broad view of testimony, I also make two remarks. First, on this account too, we can acquire knowledge of the propositions on the list, in the contexts as sketched, while it doesn't qualify as knowledge acquired by broad testimony. Take (b) for example, that the text contains a lot of metaphors: someone can know this through reading, even if this proposition is not an expression of the author's thought. The same holds for (c), that the poem is a sonnet: this can be known through reading, even when this proposition is no part of the thought that the poet wanted to express. The same holds for most, or even all, of the other items on the list. Let me just cover case (a) that may seem an exception.

It may seem an exception, because the fact that Greene's A Gun for Hire opens with "Murder didn't mean much to Raven" might be considered to express a thought that Green had about one of his fictional characters, and so as testimony. However, we must tread carefully here. For the knowledge that the reader acquires upon reading the opening page of the novel is that the first line of the book reads "Murder didn't mean much to Raven". This proposition, however, is not a thought that is expressed in the opening page of Greene's fine novel. Hence that proposition is not broadly testified by Greene, which means, in turn, that the reader's knowing that proposition on the basis of reading, is not an instance of knowing that proposition on the basis of broad testimony.

I am not going down my list any further here, as the point I want to make should be clear by now: there are cases of acquiring knowledge through reading that don't qualify as instances of acquiring knowledge on the basis of broad testimony. The point is well made even if some of the items on the list were to qualify as instances of acquiring knowledge through broad testimony.

My second remark, however, is that this account is too broad. There are expressions of thought that, intuitively, do not qualify as testimony. What prevents these expressions of thought from qualifying as testimony is that they are non-informational. Here is an example. It is a beautiful day, you are hiking in the mountains with a friend, and you say "Oh, what a beautiful day it is!" This is an expression of your thought, but it isn't testimony, for, as Lackey says, this expression of your thought "is neither offered nor taken as conveying information". (Lackey 2008: p. 21) Of course, in special circumstances, the very same expression of your thought can qualify as testimony, for 
in stance when the person your are with is blind and takes the expression of your thought as conveying the information that it is a beautiful day. What this suggests, Lackey says, is that when an expression functions merely as a conversational filler, as it does in the initial example, it doesn't qualify as testimony.

In addition to mere conversation fillers there are other kinds of expressions of thought that do not qualify as testimony. Adapting a point from Lackey, think of exhortations. You say to your son who is training for half the marathon "You can do it!" By saying this, you express a thought of yours, but it isn't testimony, as you don't offer what you say as conveying the information that your son can do it, nor does your son take what you say as conveying the information that he can do it.

Let me finally consider Lackey's so-called disjunctive account of testimony that takes its cue from the distinction between testimony as an intentional act on the part of a speaker or writer and testimony as a source of belief or knowledge for the hearer or reader (Lackey 2008: p. 27) and which forms the basis for her distinction between speaker testimony (s-testimony) and hearer testimony (h-testimony). Before presenting the full account, some terminology need be introduced. First, the notion of an "act of communication":

$\mathrm{A}$ is an act of communication iff by performing A, a speaker or writer intends to express communicable content. (It does not require that the speaker or writer also intends to communicate that content to others.)

When Plath wrote in her diary for only private purposes, she was engaging in acts of communication, as she had the intention to express communicable content, even if she had no intention to communicate that content to others. It is possible, then, to engage in acts of communication without intending to communicate to others, i.e. it is possible to express communicable content, without intending to communicate that content to others. Of course, the two intentions may go together, but the point is that they needn't.

Second, the notion of "conveying information". Acts of communication, for instance Plath's writing in her diary, "convey information". What does it mean for an act of communication A to convey the information that $\mathrm{p}$ ? Rather than defining this notion, Lackey provides paradigmatic cases. An act of communication A conveys the information that $\mathrm{p}$, she says, when, for example, (1) A is the utterance of a declarative sentence that expresses proposition $\mathrm{p}$, or $(2)$ when $<\mathrm{p}>$ is an obvious (uncancelled) pragmatic implication of A. (Lackey 2008: p. 31)

With the notions of "acts of communication" and "conveying information" thus clarified, Lackey defines speaker testimony and hearer testimony as follows:

\section{Speaker Testimony}

$\mathrm{S}$ s-testifies that $\mathrm{p}$ by performing A iff, in performing A, S reasonably intends to convey the information that $\mathrm{p}$ (in part) in virtue of A's communicable content. (Lackey 2008: p. 30)

\section{Hearer Testimony}

$\mathrm{S}$ h-testifies that $\mathrm{p}$ by performing $\mathrm{A}$ iff $\mathrm{H}, \mathrm{S}$ 's hearer, reasonably takes $\mathrm{A}$ as conveying the information that $\mathrm{p}$ (in part) in virtue of A's communicable content. (Lackey 2008: p. 32) 
The account of s-testimony requires that a speaker intends to convey information to her hearer and in that sense requires that a speaker's A be offered as conveying information. The clause "in part in virtue of A's communicable content" is included in order to exclude cases like the following: you sing in a soprano voice "I have a soprano voice" and you intend to convey the information that you have a soprano voice in virtue of the perceptual content of your sung assertion, not in virtue of the communicable content of your sung assertion; you intend to convey the information that you have a soprano voice by your singing in soprano voice, and not by the content of the words that you sing. In this case you are not s-testifying that you have a soprano voice. But you would be s-testifying that you have a soprano voice when you would just say "I have a soprano voice" or say "I have one of the women's voices, but not the alto". Had you said the latter, you would still have conveyed the information that you have a soprano voice-for there is a reasonably obvious connection between "I have a soprano voice" and "I have one of the woman's voices, but not the alto".

Whereas s-testimony requires some intention on the part of the speaker to convey information, no such intention is required for h-testimony. H-testimony captures the sense in which testimony can serve as a source of belief or knowledge for others, regardless of the testifier's intention to be such an epistemic source. Crucial for htestimony is that the hearer or reader takes the speaker's or writer's A to convey information.

It follows from these accounts that a speaker or writer can s-testify without htestifying, vice versa. But they can also go together. Lackey's official statement of the Disjunctive Account of Testimony is as follows:

$S$ testifies that $p$ by making an act of communication A iff (in part) in virtue of A's communicable content (1) S reasonably intends to convey the information that $\mathrm{p}$ and/or (2) A is reasonably taken as conveying the information that $\mathrm{p}$. (Lackey 2008: pp. 35-36)

Let me now return to the question for which the presentation of Lackey's account was propaedeutic: is all knowledge we can acquire through reading, knowledge based on Lackyan testimony? Let me go down the list. Regarding (a): as indicated, the knowledge a reader of the first line of $A$ Gun for Hire acquires through reading is that the first line of that book reads "Murder didn't mean much to Raven". This knowledge is not based on Greene's s-testimony, as Greene did not intend to convey the information that the first line of A Gun for Hire reads "Murder didn't mean much to Raven”. This is not to deny that it is possible to think up a scenario in which someone's knowing this is based on Greene's s-testimony. Suppose Jane is Greene's neighbor, and she has asked him what the title of his new book will be and what its opening sentence will be. Greene's answer is that the title is A Gun for Hire, and its opening line "Murder didn't mean much to Raven". Jane's knowledge that the first line of A Gun for Hire reads “Murder didn't mean much to Raven" in this case is based on Greene's s-testimony. But in the case as originally described, the reader acquires the indicated knowledge not through s-testimony. Nor does she acquire it through h-testimony, for it is not the case that a reader, upon reading "Murder didn't mean much to Raven" takes this to convey the information that the first line of A Gun for Hire reads "Murder didn't mean much to Raven". So, the knowledge acquired in the context as described 
in case (a) is knowledge through reading, but it is not knowledge through Lackeyan testimony.

That a specific text contains a lot of metaphorical expressions, or that it is a sonnet, or that it is humorous, as in cases (b), (c), and (d) is, in the contexts as sketched, knowledge acquired through reading. But it surely isn't acquired through the author's s-testimony: the author's acts of communication aren't intended to convey the information that the text contains a lot of metaphorical expressions, or that it is sonnet, etc. Nor is it acquired through the author's h-testimony: the reader doesn't take the author's acts of communication to convey the information that the text contains a lot of metaphorical expressions, etc. This means that the knowledge acquired in these cases is not based on Lackey testimony.

Likewise, that the article contains an invalid argument, or that the review is based on a misunderstanding, or that the book is a warning call not to harbor grudges in one's heart, or that the author assumes that p, as in (e), (f), (g) and (h), in the contexts as sketched, is known through reading. But that knowledge isn't based on either stestimony, nor on h-testimony. To write this out for (f): the reviewer certainly doesn't intend to convey the information that his review is based on a misunderstanding, so the review doesn't qualify as s-testimony; nor can a reader reasonably take the review's communicable content to express the information that the review is based on a misunderstanding, so the review doesn't qualify as h-testimony either. Which means that the knowledge acquired just isn't based on Lackey testimony.

Likewise, that the author is intimately familiar with the Scottish Enlightenment, or that what the Dutch did in de Caribbean was wrong, or that the square root of 2 is not a rational number, as in (i), (j), and (k), is, in the contexts as sketched, knowledge acquired through reading. But it isn't knowledge based on Lackeyan testimony. To write this out for $(\mathrm{k})$ : when you come to know that the square root of 2 is not a rational number, because you have read, followed and comprehended the proof, then your knowledge isn't based on s- or h-testimony, as you now "see", intellectually, for yourself that this is true.

The conclusion of this section should be clear by now. The lack of attention that reading has received among analytic epistemologists, cannot be explained by reference to the alleged fact that knowledge acquired through reading just is a token of the type knowledge acquired through testimony. What a reader may come to know through reading isn't, or isn't necessarily, coming to know through testimony. I showed that this is true given three different accounts of testimony: Coady's, Audi's (and others) and Lackey's. The list that I offered lists things that someone may come to know through reading, while the knowledge thus acquired does not qualify as testimonial knowledge. I have indicated that we may come to know any of the things on this list also through testimony, as someone may testify any of these things to us. But the point I have been eager to establish is that when we read texts, we can, in the appropriate circumstances, also just through reading come to know things. If I am correct in arguing that acquiring knowledge through reading isn't coextensive with acquiring knowledge through testimony, then there is a prima facie case that reading merits special epistemological attention. 


\section{Reading isn't just seeing words}

The second possible explanation of the inattention that epistemologists have paid to reading is that reading just is an instance of perception, and therefore merits no special attention. "Reading" is just the name for the perception of a particular kind of objects, viz. words ${ }^{5}$ and sentences. The fact that we have no special name for seeing horses, or paintings, but that we do have a special name for seeing words and sentences, this explanation says, should not seduce us into thinking that reading is in any principled way different from seeing horses and paintings.

This explanation is uncompelling. Reading is not just seeing a particular kind of objects, viz. words and sentences, whereas seeing a horse just is seeing a certain kind of animal, and seeing Van Gogh's Sunflowers just is seeing a particular painting. One is just seeing something when one is having certain visual experiences of shapes, colors, and their relative positions in one's visual field. One may just see a horse, without knowing or believing that it is a horse one is seeing, without even knowing or believing that it is an animal one is seeing, without even knowing or believing anything at all about what one is seeing. What I have referred to as just seeing, is what Fred Dretske initially called "object-perception" (as contrasted with fact-perception: seeing that the animal is a horse), and later on "simple seeing". ${ }^{6}$ According to Dretske simple seeing $\mathrm{X}$ is marked by the fact that it is compatible with having no beliefs about $\mathrm{X}^{7}$

It seems clear that reading isn't just seeing words and sentences, it isn't just looking at what are in fact words and sentences. For suppose you don't know Greek, but have opened a Greek edition of Homer's Odyssey; then you are seeing words and sentences, but you aren't reading. ${ }^{8}$ Moreover, if reading would be just seeing words and sentences, it would have to be compatible with forming no beliefs about what one is reading. But that seems wrong. One isn't reading unless one is forming such beliefs as that

- this sentence is a statement, that sentence is a question

- the word $\mathrm{W}$ that is used here, means that

- the sentence $\mathrm{S}$ that is written here, means this

- the point that the author is navigating towards seems to be $\mathrm{p}$

- given what is said about her, the main character could be a hero, but also a villain

- what the author says here, is rather implausible

\footnotetext{
5 "Words" must be understood here as including numerals and proper names.

6 Dretske (1969: chapter 1) and Dretske (2000: chapter 6). Audi (1998: p. 15) calls this 'simple perception' too.

${ }^{7}$ Simple seeing $\mathrm{X}$ and having no beliefs about $\mathrm{X}$ are compatible, even if much simple seeing in actual practice is accompanied by beliefs about X. Fact-seeing normally "builds on" simple seeing, in the sense that normally when one fact-sees that the animal is a horse, one also object-sees the horse. This is 'normally' so, but not always. For example, I can fact-see see that there is no horse in my study but that is not "built on" object-seeing a horse.

8 "Knowing a language" is a graded phenomenon, as a language can be known to rather different degrees; one person can know a particular language better than another person. But it is also the case that reading is a graded phenomenon: one person can be a better reader than another. And there is a relation between the two: the better one knows a language, the better a reader one tends to be. For an attempt to understand the metaphysics of graded phenomena, see Van Woudenberg and Peels (2018).
} 
If reading requires such beliefs to be occurrent, the requirement seems overly intellectually demanding. For when we read we don't normally form explicit beliefs about words or sentences, what they mean, or what their illocutionary force is, etc. Normally we find ourselves understanding what a sentence says or means, without forming such explicit beliefs. That is to say, normally we form such beliefs dispositionally. It is only on special occasions, such as when we read difficult passages, that we form such beliefs occurrently. But if we take the notion of "belief" to cover both occurrent and dispositional belief, then we must say that reading involves believing.

So, reading isn't just seeing. Still, there is a relation, or even multiple relations, between reading and seeing. What relation(s)? Here we do well to keep in mind that, as Nikolas Gisborne has said, "see" is a massively polysemous verb. (Gisborne 2010: p. 118) Three senses are especially relevant for present purposes. First, there is a sense that we have already encountered when discussing the notion of "object perception", which Gisborne calls the prototypical sense of"see". In this sense to "see" is to perceive visually. In such sentences as "I can see the King and the Queen from here", and "I saw the horse in the field", "see" is used in the prototypical sense. Second, "see" has a sense in which it is a knowledge ascription. And here two different classes of cases must be distinguished. First, there is the purely propositional sense of "see" that we find, for example, in such sentences as "I can see that the argument is valid", and "The King saw that the Queen was right". Here "see" has no visual meaning whatsoever. Second, there is the so-called perceptual propositional sense of "see that" that we find, for example, in such sentences as "Jane saw through the window that the child had crossed safely", and "Harold sees that it is raining". In these sentences "see" has both a prototypical sense and an epistemic sense. As Craig French has observed, "see" in propositional contexts where it has a prototypical sense, is evidential, by which he means that in such contexts "see" indicates that the source of the information in the that-clause is visual. (French 2012: p. 122)

Returning to the relation between reading and seeing, we have already observed that reading involves "seeing" words and sentences in the prototypical sense, but that it is not identical with it. If one is reading, one may be "seeing" something in another sense as well. Suppose you read in the newspaper that the Queen is in Dublin, then you may say "I see in the newspaper that the Queen is in Dublin". In this sentence "see" has not merely a prototypical sense (it is not just seeing words and sentences) but also an epistemic sense. Here "reading" involves "seeing" in the perceptual propositional sense. For "see" is used here in a propositional context and has a prototypical sense. Should we go further and say that reading is identical to "seeing" in the perceptual propositional sense? ${ }^{9}$

Let us consider this matter starting from a slightly different question. Suppose we ask ourselves whether we can know what a word or sentence means through seeing. I want to approach this question via a detour through Thomas Reid's distinction between original and acquired perception:

\footnotetext{
9 Dretske and many others as well, endorsed the so-called Entailment Thesis, according to which seeing that p, entails knowing that p. The Entailment Thesis has come under some attack in Turri (2010) and Pritchard (2012). Ranalli (2014) argues, convincingly, it seems to me, that the attack is unsuccessful.
} 
Our perceptions are of two kinds: some are natural and original, others acquired and the fruit of experience. When I perceive that this is the taste of cyder, that of brandy; that this is the smell of an apple, that of an orange ... these perceptions are not original, they are acquired. But the perception which I have by touch, of the hardness and softness of bodies, of their extension, figure and motion, is not acquired, it is original. (Reid 1764: p. 171)

The idea behind the distinction is that certain things can be perceived without any learning process, for example the hardness or softness of an object, while other perceptions do require learning, such as perceiving that this is the taste of brandy. The distinction also applies to seeing. Says Reid: "By sight we perceive originally the visible figure and color of bodies only, and their visible place". ${ }^{10}$ So original seeing includes seeing 2-dimensional shapes and patches of colors. Seeing a sphere, Reid held, is an instance of acquired perception, as it requires a learning process in which certain visual appearances become associated with certain tactile sensations. Other examples of acquired seeing are seeing that that is a horse, or seeing that it is one's neighbor's horse.

Reid's distinction can be applied to reading. Reading involves seeing little curved and straight lines on a page, which instances original perception. Original visual perceptions can be described in sentences in which "see" has the prototypical sense. For example, in the sentences "Agnes saw black little curves on a white sheet of paper", and "Agnes saw words on a page" "saw" has the prototypical sense. (I note that in these sentences "saw" denote simple seeing.)

But seeing that those little lines are Dutch words and sentences qualifies as acquired perception. For to see so much, one has to go through a learning process. Once one has the acquired perception that the little lines are the Dutch words "de", "klomp", "is" and "gebroken" respectively, one may furthermore see that these words, in this order, jointly constitute a grammatical Dutch sentence, which is yet another instance of acquired perception. These acquired perceptions can be described by sentences in which "see" has the perceptual propositional sense, as, for example, in the sentences "Agnes saw that the little lines formed a Dutch word", and "Agnes saw that the words compose a Dutch sentence". (I note that "saw" in these sentences is fact-perception.)

Upon seeing that the sequence of Dutch words "de", "klomp", "is" and "gebroken" form a grammatical sentence, one may "see" that that sentence expresses the proposition that the wooden shoe is broken. This is, again, an acquired perception. But this kind of acquired perception cannot be described by sentences in which "see" has the perceptual propositional sense. It can only be described by sentences in which "see" has the purely epistemic sense. Take for example the sentence "Agnes saw that the string of Dutch words expresses the proposition that the wooden shoe is broken." Here "saw" has no visual sense at all. (I note that here too "saw" denotes fact-perception.)

So, reading involves "seeing" in different senses:

10 Reid (1764: p. 171). Reid, then, like Berkeley, held that what is given originally to sight is only twodimensional (colors and 2D shapes, and 2D locations), and that three-dimensional shapes (cubes, spheres, etc.) are given originally only to touch. Van Cleve has argued that Reid and Berkeley were wrong here, due to the at the time unknown mechanism of stereopsis (Van Cleve 2015: pp. 486-487). But even if Van Cleve is right, and Reid wrong here, this doesn't vitiate the distinction between original and acquired perception. 
1. just seeing little lines, just seeing words and sentences (original seeing; "see" has the prototypical sense)

2. seeing that the little lines are words and sentences (acquired seeing; "see" has the perceptual propositional sense)

3. seeing that the sentences express a particular proposition (acquired seeing; "see" has the purely epistemic sense)

Some more illustrations of "see" in the purely epistemic sense, used in the context of reading, might be helpful. When someone says, upon reading a particular text, that she now "sees" that the word 'scientism' is not used by its author in a pejorative way, then "see" is used in the purely epistemic, non visual, sense. When we read, and on that basis acquire a sense of what the words and sentences mean and "see" what the writer intended to say, then "see" is again used in a purely epistemic sense. Finally, when we don't know what "to procrastinate" means, consult a dictionary and there "see" that it means "to put things of", "see" is again used in the purely epistemic sense.

All of this goes to show that reading isn't just seeing, which is the main point of this section. But what I said also goes to show that reading is not merely "seeing" in the perceptual propositional sense, but that it also involves "seeing" in the purely epistemic sense.

\section{What is reading? An analysis}

In this section I offer an analysis of reading, by formulating necessary and sufficient conditions for "person S is reading". The previous section already made a start on this, by noting that someone may be just seeing words and sentences, and yet not be reading, because she doesn't know that what she is seeing are words. This strongly suggests that (object-)seeing words and sentences is insufficient for reading, even if it is necessary for it.

One may also (fact-)see words and sentences, for instance see that what one is looking at are words, or see that they are Italian or Dutch words, but still not be reading. For example, you may know enough to be able to see that the words you are looking at are Italian or Dutch words, but since you don't know what the words mean and have no grasp of the syntax of these languages, you still aren't reading. One isn't reading in these cases, because one doesn't know the language, or doesn't know it well enough. This strongly suggests, first, that fact-seeing words and sentences is insufficient for reading, even if it is necessary for it; and second that knowing the language to which the words belong is also necessary for reading.

Now one may (object-)see the words, fact-see that they are Italian or Dutch words, and even know these languages (so know what their words mean, know their syntaxes) and still not be reading. The graphic designer who is working on the lay-out of the pages of a book that is to be published, (object-)sees words, sees that they are English words, and, even knows the language, and yet may not be reading, for example because she is not focused on the content of the words, isn't trying to get a sense of what the words jointly mean. This strongly suggests that focusing on the 
content, trying to get a sense of what the words jointly mean, is also necessary for reading. 11

This condition rules out the following interactions with words as instances of reading: someone is reading aloud words that belong to a language that he knows, but he does it, so to speak, "mechanically"; he reads up the words alright, but he is not attending to their content, not to what they mean. That person is parroting, i.e. "articulating sounds that have meaning", but isn't reading. So-called "reading-machines", pieces of assistive technology that scan words and sentences and use a speech synthesizer to read them out loud, are also parroting; they aren't reading.

The expression "what words jointly mean", is complex ${ }^{12}$ but I intend it to cover the meaning sentences ${ }^{13}$ as well as the meaning of paragraphs or even larger textual unit. ${ }^{14}$ The meaning of these items can be understood, or apprehended, with greater or lesser accuracy, in greater or lesser depth. But some apprehension of the joint meaning of words is required if there is to be reading. That is why stones and cats are incapable of reading - they don't understand, or apprehend, the joint meaning of words. This is not to deny that certain animals can be trained to respond to words and sentences in ways that mimic the responses of humans who do apprehend their meaning. Upon being confronted with a blackboard on which the words "Now stamp with your right leg five times!" are written, both a horse and a person may respond by stamping five times with their right leg. But only be the person, not the horse, has read the words, as only the person, not the horse, has understood the joint meaning of the words. The horse is at best trained to behaviorally respond in a certain way to what are in fact words composing a sentence, but doesn't understand the words, because he doesn't see that they are words, and doesn't know the language to which they belong.

It should be noted that a person can be reading even when he misapprehends the words, when he misunderstands what they mean. That is why, as we say, there are good, not so good, and bad readers. But even bad readers are readers, as they have some kind of understanding, some form of apprehension of what the units they are reading mean. It should also be noted that a person is still reading, even when she is unsure about the precise meaning of certain words, or passages.

The discussion so far suggests the following analysis of reading:

$\mathrm{S}$ is reading, iff

(i) S object-sees words and sentences;

(ii) S knows the language to which the words and sentences belong;

(iii) $\mathrm{S}$ fact-sees words and sentences, i.e. $\mathrm{S}$ believes (mostly dispositionally) that what she is looking at are words and sentences that belong to this particular language, that this particular words means such and so, etc.

\footnotetext{
11 Like "knowing a language" (see fn. 8), "getting a sense of the content, or capturing what the words jointly mean" is a graded phenomenon too. One reader can have a much better sense of what the words read jointly mean than another. So this condition too indicates a dimension in which one person can be a better reader than another. The condition suggests that the greater one's understanding of the joint meaning of the words read, the better a reader one is.

12 See for that Van Woudenberg (2018: pp. 112-122).

13 See Alston (2000): chapters 6 and 7.

14 A still very informative discussion of this notion is Skinner (1969).
} 
(iv) S acquires, through object- and fact-seeing the words and sentences, some understanding of what the words and sentences jointly mean.

Three remarks should further elucidate this account. One. My analysis of reading is in terms of seeing. However, blind people who have mastered Braille can also read. For although they can't see words and sentences, they can touch them-and touch them in such a way that by touching them, they acquire a sense of what the words jointly mean. Isn't that reading? Well, if one thinks about reading in more general terms, for instance in terms of one's sense organs "taking in" words with the effect that one thereby acquires an understanding or apprehension of what the words jointly mean, blind people using Braille can read. However, this approach also renders listening to an audio book an instance of reading, which is unwanted, as it entails that even analphabetic persons can read, which is a contradiction in terms. We should therefore, perhaps, say that in a literal sense only a seeing person can read-but that in an analogical sense also blind persons that know Braille can read. It is an interesting exercise to provide an account of reading in an analogical sense that doesn't entail that listening to an audio book also qualifies as reading. I leave that for another occasion.

Two. Gestalt-psychologists have argued that when humans form a "percept" (a Gestalt), the "whole" of what is perceived has a reality of its own, that is, in a way that I won't try to specify, independent of the reality of the perceived parts. We can see a whole face even if we are only subsidiarily aware of the face's parts; the reality of seeing a whole face is, in some way, independent of seeing the parts that jointly compose the face. Reading also involves Gestalt-perception, in the sense that at least experienced readers don't read texts by reading letter by letter and word by word. Rather they read by seeing larger "wholes", not individual letters, but whole words; and often not even individual words, but entire parts of sentences, and even full sentences (when they are not too long). That is why clause (iii) explains S's fact-seeing letters and words dispositionally: even if, when reading, readers mostly don't form occurrent beliefs such as this is the letter "E", or here is the word "Everything", they do either dispositionally believe such things (in the way you dispositionally believe that Paris is the capital of France even when sound asleep, or mentally occupied by rather different matters) or have a disposition to believe them (in the way you have a disposition to believe you are shorter than $40 \mathrm{~m}$ upon being asked whether you are-and you have never ever entertained the proposition I am shorter than $40 \mathrm{~m}$ ).

Three. The proffered analysis isn't committed to any view how reading and "interpreting" relate. It is not assuming that reading always involves interpretation, nor that it never does, nor that it sometimes does. The proposed analysis of reading is supposed to be such that the activity picked out by it, may yield knowledge of propositions of the sort listed in the beginning of Sect. 1. ${ }^{15}$

With this account of reading in place, I next discuss how to specify the source of knowledge that is, or is associated with, reading.

\footnotetext{
15 It may be objected: doesn't the account, focused as it is on words and meaning, imply that one cannot read the alphabet, as the letters of the alphabet aren't words and individually (except from the alphabet's first letter and the letter between ' $h$ ' and 'j') don't mean anything? My response is: right, that isn't reading; it fails the reading conditions. So when we say "S is reading the alphabet", we are using "reading", compared to Braille reading, in an even further extended analogical way.
} 


\section{Reading as a source of knowledge}

I have argued in Sects. 1 and 2 that we can come to know many things through reading, where reading is not attending to testimony, nor just seeing words and sentences. In other words, I have argued that reading is a source of knowledge that is coextensive with neither testimony, nor visual perception. However, the precise delineation of that source requires more attention. For what exactly, in the case of reading, is that "something in the life of a knower" that yields belief that can constitute knowledge? Three initially perhaps somewhat plausible candidates present themselves:

(A) words and sentences

(B) the reading of words and sentences

(C) the reader's emotive, logical, moral and other kinds of responses to the reading of words and sentences.

Candidate (A) can be written off almost immediately, as words on surfaces as such don't yield beliefs, just as horses and paintings as such don't yield perceptual beliefs. It is the reading of words and sentences that yields belief, just as it is the perception of horses and paintings that may yield belief. Yet we cannot simply settle on (B) as the best delineation of the source that reading is.

For the following reason. One of the things that we may come to know through reading, I suggested in Sect. 1, example (d), is that a particular book humorous (Kingsley Amis's Lucky Jim, for example), or horrifying (Bram Stoker's Dracula, for example). However, we might need to be a bit more specific here. For the question arises: do we come to know these things (assuming we do come to know them) through reading (these) books, or do we come to know this through reading these books and through noticing our emotive responses to what we read? If the former, then (B) is a sound delineation of the source, but if the latter, then (C). The argument for (C) is that we laugh out loud when we read Amis, and likely feel scared when we read Stoker, and that hadn't we actually had these emotive responses, we wouldn't have known through reading these books that they are humorous and horrifying respectively. ${ }^{16}$ These examples suggest that the emotive responses we have while reading should be considered parts of the "something" in the life of the knower that can yield belief constituting knowledge.

In the same vein, we can come to know through reading, as in (e) on the list, that the article contains an invalid argument. But we cannot come to know this through reading, unless we also attend to our logic-sensitive responses to the argument that is presented in the article. This suggest that our logical responses to what we read must also be considered as parts of the source of knowledge that is associated with reading. This logical response is also operative in example (h), where the reader comes to know that the author assumes that $\mathrm{p}$, as that is the inevitable though unobvious conclusion from what the author explicitly says. It is also operative in example (k), where the reader comes to know, through reading the proof, that the square root of 2 is not a rational number.

\footnotetext{
16 It goes without saying that we could also come to know that these books are humorous and horrifying not through reading these books themselves, but because some authoritative person reports this fact.
} 
Also, one can come to know through reading, as in example (f), that the review is based on a misunderstanding. But in order to come to know this that way, one must remember what the work reviewed did say. So, to obtain the knowledge as described in (e), one must attend to what is stored in one's memory, which suggests that the memorial responses to what is read must be considered part of the source that is associated with reading. This memorial response also accounts for example (i), where the reader comes to know that the author is intimately familiar with the Scottish Enlightenment.

Acquiring the knowledge that what the Dutch did in the Caribbean was wrong, as in example (j), from reading a 'clean' statement of facts and figures, requires that the reader attains to his moral sensibilities. These sensibilities should therefore also be considered as parts of the source of knowledge that is associated with reading.

Likewise, we can come to know that words are aesthetically pleasing, beautiful, sublime, uplifting, grave and the like; again in order to come to know this through reading, we must attend to the responses of our aesthetic sensibilities while reading.

The conclusion of this section thus seems to be that the "something" in the life of the knower that is connected with reading and that yields beliefs that constitute knowledge, is delineated by (C) rather than by (B). The source of knowledge that reading is, is the reader's emotive, logical, moral and other kinds of responses to the words and sentences read.

However, it is also possible, given the cases that I have presented, to conclude that (B) delineates the source that reading is, and add to this that reading works the cognitive effects (provides knowledge) as specified in the cases on the list, often in conjunction with other sources. Case (e), for example, in which one comes to know through reading that the article contains an invalid argument, should then be analyzed as a case in which reading works its cognitive effect in conjunction with reason: through reading one comes to know what the argument is, and through reason one comes to know that it is invalid. And case (f), coming to know through reading that the review is based on a misunderstanding, should then be analyzed as a case in which reading works in conjunction with memory and reason: through reading one comes to know what it is that the reviewer says about the book, and in conjunction with memory and reason one comes to know that what the reviewer says is based on a misunderstanding. Similar kinds of things could be said about the other cases.

It seems to me that we should prefer the latter conclusion over the former. The reason is that someone can come to know through reading what the argument in the article is, and not see that it is invalid; yet that person has certainly read the article, and through it he has come to know what the argument was, even if his logical acumen left him. Or one can come to know through reading the facts and figures related to the Dutch presence in the Caribbean, and fail to come to know that what the Dutch did was wrong; yet the person has surely read the facts and figures, even if his moral sense didn't work as it should. So, the reason why we should prefer the latter conclusion is that it more elegantly accounts for cases of these kinds, i.e. cases in which sources do not work in conjunction with each other. 


\section{The kind of source that reading is}

In this section I attempt to further characterize the kind of source that reading is. I present some well-known distinctions that epistemologists have used to differentiate between kinds of sources, and apply them to reading.

Ernest Sosa has said, "There are faculties of two broad sorts: those that lead from beliefs to beliefs, and those that lead to beliefs but not from beliefs". (Sosa 1991: p. 225) The former he calls transmission faculties, the latter generation faculties. An example that he offers of the former is rationalist deduction: you believe that you are $1.94 \mathrm{~m}$, from which you deduce that you are shorter than $30 \mathrm{~m}$-which is a proposition that you also believe. An example that he offers of the latter is visual perception: this may generate the belief that the object you are looking at is round and yellow.

Sosa's distinction can be recast in terms of "sources". If we do that, we can see that reading often is a transmission source: I read your message that you will arrive at O'Hare airport next Tuesday on 6 pm: this is something you believe, and even know, and that $\mathrm{I}$, through reading your message, now also believe (and know). However, reading is not only a transmission source. For as I have suggested, someone may come to know, by reading the book, that Lucky Jim is a very funny. Coming to know this that way, however, is not a matter of belief transmission. It isn't that Kingsley Amis believed the book to be funny, and that he made This book is funny part of the propositional content of the book, and that I, by reading the book, picked up that proposition. Reading the book didn't transmit belief or even knowledge, but generated it. In a similar vein: one may come to know, as in example (j), that what the Dutch did in the Caribbean was wrong by reading a 'clean' statement of facts and figures; if we assume that the author of the statement had no evaluative response to these facts and figures, it seems clear that when you come to know, through reading, that what the Dutch did was wrong, is not a matter of transmission but of generation of belief. So, reading is both a transmission and a generative source.

Audi distinguishes between sources that are 'basic' in the sense that they "yield knowledge without positive dependence on the operation of some other source of knowledge" and sources that are non-basic. (Audi 2002: p. 72) Perception and reflection, he argues, are basic sources. One might know through perception that the flowers are yellow, and one might know through reflection that if two persons are first cousins, they share a pair of grandparents. In neither case does this knowledge positively depend on the operation of other sources. At the same time a basic source may be negatively dependent on the operation of some other source, in that one may acquire a defeater from other sources for a belief yielded by a basic source. If you believe, upon seeing them, that the flowers are yellow, but also remember that the shopkeeper tends to manipulate the lightning, then, even if the flowers are in fact yellow, your belief doesn't constitute knowledge. This negative dependence on memory, however, doesn't compromise the basicality of perception.

Reading is not a basic source-it is not a source that "yields knowledge without positive dependence on the operation of some other source of knowledge". As argued in Sect. 2, reading is positively dependent on perception. It is also positively dependent on memory; for when one reads a paper or newspaper or whatever, one needs to have some recollection of the earlier parts of what one has been reading in order to get a 
sense of what the words jointly mean. Also, as was argued in the previous section, reading is also positively dependent on sources like our aesthetic and moral sense, our reason and memory. There are many things we could not know through reading that we in fact can come to know through reading, without these other sources lending a helping hand.

Audi qualifies a source of knowledge as "essential" if "what we think of as "our knowledge' in an over all sense would collapse" without it. (Audi 2002: p. 74) He argues that memory, while not a basic source (as we cannot know anything from memory without coming to know it through some other source earlier), is an essential source. For without memory we would only know those parts and aspects that present themselves immediately to our senses. We wouldn't recognize things, we wouldn't know the past. Without memory, what we think of as 'our knowledge in an overall sense' would collapse indeed. ${ }^{17}$

Audi's category suggests there might also be epistemically inessential sources. Audi gives no examples, but might reading be one? Prior to the invention of writing, reading was not a source at all, and a fortiori not an essential source. Since the invention of writing, reading, for most people, seems to have been an inessential source, one that, although perhaps convenient, is not necessary to keep "what we think of as our knowledge in an overall sense" in tact. As we reach our own times, however, and note the ubiquity and centrality of the written media, the expansion of libraries and the world wide web, it seems that without reading these media, "what we think of as 'our knowledge' in an overall sense" would collapse indeed. Reading once was an inessential source, but as time went by it became for ever more people an essential source.

Audi defines a "unique source of knowledge" as a source that yields knowledge that "is not otherwise acquirable". (Audi 2002: p. 75) What we know through memory, can sometimes also be known through perception. One may remember that the flowers are wilting, but one may also see that they are. This means that neither memory nor visual perception is a unique source.

Is reading a unique source of knowledge? In many cases it is not. Much knowledge acquired through reading can or could also be acquired through some other source. Through reading so much in the newspaper, I may come to know that the Tate Gallery is open again; but I may also come to know this by just seeing that it is open again. However, a case could be made that sometimes at least reading is a unique source, depending on the sort of text that the words one is reading belong to. Reading certain kinds of poetry, for instance, or reading elaborate historical narratives may yield in a reader beliefs that constitute knowledge that could not be yielded by any other source. That particular knowledge of human psychology that can be yielded by reading John Steinbeck's Of Mice and Men, may, perhaps, not be yielded by any other source. ${ }^{18}$ If this is correct, reading can sometimes be a unique source of knowledge.

\footnotetext{
17 BonJour (1998) is a forceful argument for the claim that reason (apriori rational insight) is an essential source.

18 A point in this direction is made by Gibson (2009).
} 


\section{Conclusion}

What I have been arguing, then, is, first, that reading isn't coextensive with attending to testimony, nor with just seeing words and sentences. Next I proposed an analysis of reading in terms of (i) object-seeing words and sentences, (ii) knowing the language to which the words belong, (iii) fact-seeing words and sentences, so forming beliefs about them, (iv) an apprehension of what the words jointly mean. Next I argued that the source of knowledge that reading is, often works its cognitive effects in conjunction with other sources. Finally I suggested that the source of knowledge that reading is, is both transmissive and generative, non-basic, once not essential, but currently essential for many people, and sometimes unique. ${ }^{19}$

Open Access This article is distributed under the terms of the Creative Commons Attribution 4.0 International License (http://creativecommons.org/licenses/by/4.0/), which permits unrestricted use, distribution, and reproduction in any medium, provided you give appropriate credit to the original author(s) and the source, provide a link to the Creative Commons license, and indicate if changes were made.

\section{References}

Alston, W. P. (1993). The reliability of sense perception. Ithaca, NY: Cornell University Press.

Alston, W. P. (2000). Illocutionary acts and sentence meaning. Ithaca: Cornell University Press.

Audi, R. (1998). Epistemology. London: Routledge.

Audi, R. (2002). The sources of knowledge. In P. K. Moser (Ed.), The Oxford handbook of epistemology (pp. 71-94). Oxford: Oxford University Press.

BonJour, L. (1998). In defense of pure reason. Cambridge: Cambridge University Press.

BonJour, L. (2002). Epistemology. Classic problems and contemporary responses. Boulder: Rowman \& Littlefield.

Chisholm, R. (1957). Perceiving. A philosophical study. Ithaca NY: Cornell University Press.

Chisholm, R. (1977). Theory of knowledge (2nd ed.). Englewood Cliffs: Prentice-Hall.

Coady, C. A. J. (1992). Testimony. A philosophical study. Oxford: Clarendon.

Dancy, J. (1985). Contemporary epistemology. Oxford: Blackwell.

Dretske, F. (1969). Seeing and knowing. Chicago: University of Chicago Press.

Dretske, F. (2000). Simple seeing. In F. Dretske (Ed.), Perception, knowledge, and belief. Selected essays (pp. 97-112). Cambridge: Cambridge University Press.

Faulkner, P. (2011). Knowledge on trust. Oxford: Oxford University Press.

Foley, R. (2001). Intellectual trust in oneself and others. Cambridge: Cambridge University Press.

French, C. (2012). Does propositional seeing entail propositional knowing? Theoria, 78, 115-127.

Fricker, E. (1995). Telling and trusting: Reductionism and anti reductionism in the epistemology of testimony. Mind, 104(1995), 393-411.

Gelfert, A. (2014). A critical introduction to testimony. London: Continuum.

Gendler, T. S., \& Hawthorne, J. (Eds.). (2006). Perceptual experience. New York: Oxford University Press.

Gibson, J. (2009). Literature and knowledge. In R. Eldridge (Ed.), The Oxford handbook of philosophy and literature (pp. 467-485). Oxford: Oxford University Press.

Ginet, C. (1975). Knowledge, perception, and memory. Dordrecht: Reidel.

Gisborne, N. (2010). The event structure of perception verbs. Oxford: Oxford University Press.

\footnotetext{
19 For comments on material presented in an earlier version of this paper I am much indebted to Valentin Arts, Lieke Asma, Robert Audi, Wout Bisschop, Hans van Eyghen, Naomi Kloosterboer, Jennifer Lackey, Baron Reed, Rik Peels, Chris Ranalli, Jeroen de Ridder, Emanuel Rutten, and Nick Wolterstorff. Work on this paper was made possible by a grant from the Templeton World Charity Foundation on "The Epistemic Responsibilities of the University". The views expressed in this paper are those of the author, and don't necessarily coincide with those of the Foundation.
} 
Lackey, J. (2008). Learning from words. Testimony as a source of knowledge. Oxford: Oxford University Press.

McMyler, B. (2011). Testimony, trust, and authority. Oxford: Oxford University Press.

Moser, P. (1989). Knowledge and evidence. Cambridge: Cambridge University Press.

Moser, P. K., Mulder, D., \& Trout, J. D. (1998). The theory of knowledge. New York: Oxford University Press.

Plantinga, A. (1993). Warrant and proper function. New York: Oxford University Press.

Pritchard, D. (2006). What is this thing called knowledge?. London: Routledge.

Pritchard, D. (2012). Epistemological disjunctivism. Oxford: Oxford University Press.

Ranalli, C. (2014). Luck, propositional perception, and the entailment thesis. Synthese, 191, 1222-1247.

Reid, T. (1764 [1997]). An inquiry into the human mind on the principles of common sense. In D. Brookes (Ed.). Edinburgh: Edinburgh University Press.

Skinner, Q. (1969). Meaning and understanding in the history of ideas. History and Theory, 8, 3-53.

Sosa, E. (1991). Knowledge in perspective. Cambridge: Cambridge University Press.

Turri, J. (2010). Does perceiving entail knowing? Theoria, 76, 197-206.

Van Cleve, J. (2015). Problems from Reid. Oxford: Oxford University Press.

Van Woudenberg, R. (2018). The nature of the humanities. Philosophy, 93(2018), 109-140.

Van Woudenberg, R., \& Peels, R. (2018). The metaphysics of degrees. European Journal of Philosophy, 26(2018), 46-65.

Wittgenstein, L. (2009). Philosophische Untersuchungen/Philosophical investigations (G. E. M. Anscombe, P. M. S. Hacker \& J. Schulte, Trans.; revised 4th ed.). London: Wiley-Blackwell.

Publisher's Note Springer Nature remains neutral with regard to jurisdictional claims in published maps and institutional affiliations. 